\title{
PERCEIVED SOURCES OF STRESS AND COPING STRATEGIES AMONG UNDERGRADUATE DENTAL STUDENTS IN PUBLIC UNIVERSITY AND PRIVATE UNIVERSITY (Cross sectional study)
}

\begin{abstract}
Ghada N.Ghazal ${ }^{*}$ BDS, Hala Amer ${ }^{2}$ PhD,Wafaa Essam² PhD.
\section{ABSTRACT}

INTRODUCTION: Dental Students are requested to acquire various academic competencies and accomplish multiple clinical and interpersonal skills. This usually places them in stressful situations that might need different coping strategies to decrease their level of stress and anxiety. OBJECTIVES: The aim of this study was to identify the perceived sources of stress among clinical and preclinical undergraduate dental students, in public and private universities. Furthermore, coping strategies adopted by students were also investigated.

MATERIALS AND METHODS: A cross-sectional, analytical study, using a specially designed questionnaire, was adopted during spring 2019 academic semesters. A minimal sample size of 309 students was determined from both universities. Therefore, all students who were available at the time of the survey, in the third preclinical and fifth clinical undergraduate years, in both faculties of dentistry, were approached (375 students). The questionnaire comprised two main sections. The first section dealt with socio-demographic information regarding the students' gender, age, nationality and academic year of undergraduate study. The second section dealt with the possible stressful situations including a list of stressors covering seven main domains.

The seven domains, involved stressors, related to self-efficacy beliefs, faculty and administration, workload, patient treatment, clinical training, performance pressure, social stressors. The questionnaire also enquired about the various coping strategies used by the students to relieve any stressors such as self -distraction, active coping and planning.

RESULTS: Only 358 students returned the filled questionnaire sheets, giving a response rate of nearly 95\%. Among all domains of stress included in the questionnaire, workload had a mean score of $(19.52 \pm 3.46)$ and $(16.83 \pm 4.31)$ among public and private university students, respectively, representing the highest sources of stress. Moreover, the commonly adopted coping mechanisms by students were comfort in religion or spiritual beliefs (88.3\%) and praying or meditating (88\%), respectively. The multivariable regression analysis, showed that males were almost 5 times less stressed than females $-4.91(-7.70,-2.13)$ and students of the public University were 6.65 times more stressed than those enrolled in private University $6.65(3.90,9.40)$. Moreover, students of preclinical years were 11.41 times less stressed than those in the clinical years-11.41 (-15.51, -7.30$)$. CONCLUSION: Students of both faculties, whether private or public, suffered from different sources of stress, especially those relating to workload as well as faculty and administration, indicating a need to reduce these stressors and to encourage constructive coping mechanisms.
\end{abstract}

KEY WORDS: Stress, dental students, coping mechanisms, Alexandria, Egypt.

RUNNING TITLE: Stress among dental students of public and private Faculties.

1 Dentist at Ministry of Health.

2 Professor of Public Health Department, Faculty of Dentistry, Alexandria University, Alexandria, Egypt.

*Corresponding author:

Email:drghadaghazal@hotmail.com

\section{INTRODUCTION}

Studying dentistry is a demanding and stressful exposure that requires development of various clinical, theoretical and interpersonal skills during academic education(1). In the preclinical years, students are usually faced with significant effort, manual skills and time constraints in order to accomplish their laboratory requirements. The clinical part, on the other hand, also subjects the students to multiple sources of stress and, consequently higher risk for psychological problems and probably lower academic achievement $(2,3)$.
Assessment of the potential stressors, during years of education, would help, both students and faculty, to detect the sources of stress and address the appropriate coping strategies. It will also enable students to manage their stress and improve their educational performance (4-6). Consequently it would help them manage stress in their future professional activities (5). Therefore, the present study was, planned to update the information provided by previous studies $(7,8)$ regarding sources of stress, as clinical factor stressor was the first rank among Alexandria University reported in these studies, and to compare levels of stress in public university to the only new private university present in Alexandria. This was not present 
at the time of conduction of the previous studies. Moreover the present study was planned to detect coping strategies adopted by dental students as both previous studies did not assess those strategies. The null hypothesis of the current study is that no significant differences, in stress levels, between Alexandria and Pharos University dental students would be expected.

The objectives of the current study are general and specific objectives. The general objective is to determine the perceived sources of stress, and the coping mechanisms used by undergraduate dental students. While the Secondary objective is to compare these parameters between dental students in public and private universities, namely Alexandria University and Pharos University, in relation to the various sociodemographic variables such as age, gender and academic year.

\section{MATERIALS AND METHODS \\ Study design}

A cross-sectional, analytical study was carried out, among third and fifth year undergraduate dental students, at both faculties of dentistry, in Alexandria University and Pharos University, during spring 2019 academic semesters

\section{Setting}

The study was done in Alexandria public University and Pharos private University.

Public Universities are funded by the government, so they receive low fees, In the other hand Private Universities are funded mainly by their students' fees.

The approval of the Research Ethics Committee of the Faculty of Dentistry, Alexandria University, was initially taken on 13/1/2019 (IRB No 00010556-IORG 0008839).

The administrative authorities, in both Alexandria and Pharos Universities, were then approached, and the aim and objectives of the study were explained to them in order to secure their approval and assistance for conduction of the study. The informed consent was oral implicit and returning back the filled questionnaire was as a proof for agreement of the participants to participate in the study. The study duration was about 3 months.

\section{Participants and sample power calculation}

A minimal sample size of 309 students was estimated based on previous literature review (9). The total number of third and fifth year students, in both faculties, was 1562, the prevalence of stresses and coping strategies among dental students in Alexandria were anticipated to be $50 \%$. By using a power of $80 \%$, precision $5 \%, \alpha=0.05$, the minimal required sample size per group was found to be 309 students (10). However, all available students during the time of the study were approached in order to compensate for the expected low response rate. The sample size was calculated according to Charan and Biswas (2013)(11). The researcher; therefore, included all students who were available and willing to participate at the time of study conduction (convenience sample).

\section{Variables}

Outcome variables are potential stressors and coping mechanisms. Mean and standard deviation were calculated for all quantitative variables, Which are the 7 domains of stress of the questionnaire that represent self-efficacy beliefs, Faculty and administration, Workload, Patient treatment, Clinical training, Performance pressure and social stressors. Potential cofounders are demographic information which are: gender, age, year of undergraduate study and grade in previous year.

\section{The study instrument}

The study was carried out using a self-administered questionnaire that was designed based on a literature review (modified version of the dental environment stress survey, the perceived stress scale, the general self-efficacy scale and brief coping scale)(9), that was used in its original English language and distributed by the researcher herself not by any employee of both universities.

The questionnaire comprised two main sections. The first section dealt with socio-demographic information regarding the students' gender, age, nationality and academic year of undergraduate study. The second section investigated the possible sources of stress that were included in seven main domains. The first domain involved stressors related to selfefficacy beliefs such as lack of confidence to be a successful student, and fear of failing the course or the year. The second domain involved stressors related to faculty and administration such as inconsistency of feedback on work between different instructors, stressful atmosphere created by faculty members and lack of adequate clinical staff in the clinics. The third domain involved stressors related to workload such as lack of time to complete clinical requirements as well as lack of time for relaxation. The fourth domain inquired about stressors related to patient treatment such as patients being late or not showing for their appointments and working on patients with bad oral hygiene. The fifth domain included stressors related to clinical training such as difficulty in learning clinical procedures and difficulty of manual dexterity. The sixth domain asked about stressors related to performance pressure such as competition for grades. The seventh domain was concerned with social stressors such as financial responsibilities and neglect for personal life. The questionnaire also enquired about eight coping strategies used by the students to relieve any stressors such as self-distraction and active coping with yes or no answers.

The participants assessed the stressors on a 4-points Likert scale (not stressful, slightly stressful, moderately stressful and severely stressful) that was converted into a quantifiable estimation using mean and standard deviation. To avoid bias the questionnaire was anonymous. It was self- applied to avoid any influence on the answers from the researcher.

\section{Validity test}

Validation included assessment of face validity and content validity as follows:

a) Face validity: It was checked by three post graduate students who reviewed the form to ensure that the instrument was appropriate to participants.

b) Content validity: It was examined by three of the faculty staff members who systematically reviewed the form to ensure that it included the important content items.

\section{Reliability test}

The internal consistency of the questionnaire was calculated using cronbach's alpha internal consistency indicator to estimate the reliability of the 7 domains of the questionnaire 
form. Cronbach's alpha for the whole form was 0.81 which indicated good internal consistency and was acceptable for all domains (more than o.6) (Table 2).

Table 1: Internal consistency of all domains using Cronbach $\alpha$

\begin{tabular}{|c|c|c|}
\hline & Cronbach's $\alpha$ & $\begin{array}{c}\text { Number of } \\
\text { items }\end{array}$ \\
\hline D1-Self-efficacy beliefs & 0.71 & 5 \\
\hline $\begin{array}{c}\text { D2-Faculty and } \\
\text { administration }\end{array}$ & 0.79 & 7 \\
\hline D3-Workload & 0.80 & 6 \\
\hline D4-Patient treatment & 0.91 & 4 \\
\hline D5-Clinical training & 0.86 & 2 \\
\hline D6-Performance pressure & - & 1 \\
\hline D7-Social stressors & 0.67 & 3 \\
\hline All Domains & 0.89 & 28 \\
\hline
\end{tabular}

\section{Quantitative variables}

Mean and standard deviation were calculated for all quantitative variables. Multivariable regression analysis was done to determine the effect of different factors and stress coping mechanisms on total stress level among Alexandria and Pharos University students. Significance was set at P $\leq 0.05$. Data was analyzed using IBM SPSS statistical software (version 25).

\section{Statistical analysis}

Results of the present work started by calculating the internal consistency of the questionnaire domains. Then, descriptive data were presented in frequency and percentage for qualitative variables (characteristics of the study population), while means and standard deviations were calculated for all quantitative variables. Multivariable regression analysis was done to determine the effect of different factors and stress coping mechanisms on total stress level among Alexandria and Pharos University students. Significance was set at $\mathrm{P}$ $\leq 0.05$. Data was analyzed using IBM SPSS statistical software (version 25).

\section{RESULTS}

A number of 375 students were approached out of which 358 students agreed to complete the questionnaire, giving rise to a response rate of nearly $95 \%$. The final sample included in the study was 161 students from Alexandria (about 45\% from the total number) and 197 from Pharos University, (about 55\% from the total number) as this was approximately the original proportion of students in these two academic years at the time of study conduction. The participation was voluntary and all participants were assured about the confidentiality of data and about the right to withdraw from the study at any point with no penalties.

In both faculties of dentistry, students were approached during their preclinical (56 students from Alexandria University and 100 students from Pharos University) and clinical sessions (105 students from Alexandria University and 97 students from Pharos University). They were encouraged to participate in the study by thoroughly explaining the importance of obtaining an accurate measure of students' stressors to suggest recommendations to make the educational environment be more conductive for positive learning. The questionnaire was anonymous to gain the participants' trust and returning back the filled copy was considered an implicit consent to participate in the study (figure 2).
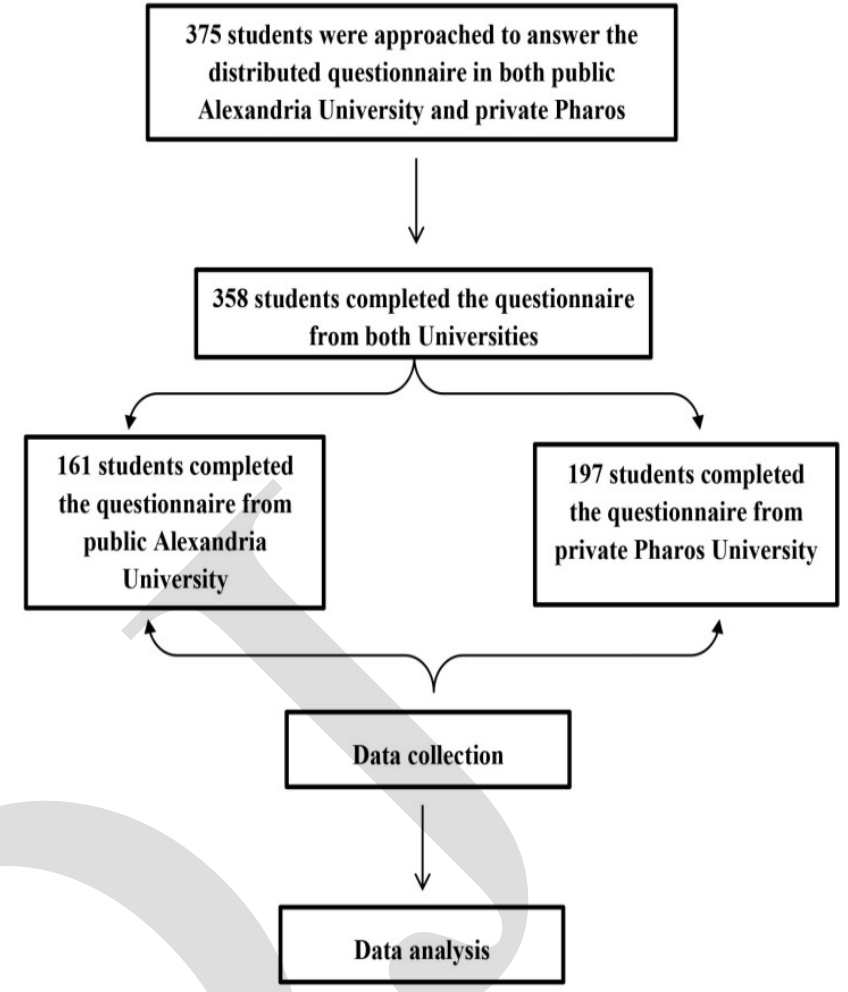

Figure (2): Flow chart

In Alexandria University, the students' mean age was (21.94 \pm 1.17), with females representing about three quarter of the study participants (73.3\%), and (65.2\%) were in their clinical years compared to Pharos University where the mean age was (21.74 \pm 1.37) and males accounted for (57.4\%), with(49.2\%)being in their clinical years. Excellent grade was the most frequent among students in Alexandria University (38.5\%) compared to good grade (62.1\%) Pharos University (Table 2).

Table (2): Comparison between Alexandria and Pharos University students regarding demographic characteristics

\begin{tabular}{|c|c|c|c|}
\hline Independent Variables & $\begin{array}{c}\text { Alexandria University } \\
(\mathrm{n}=161)\end{array}$ & $\begin{array}{c}\text { Pharos University } \\
(\mathrm{n}=197)\end{array}$ & P Value \\
\hline $\begin{array}{ll}\text { Age }^{a} & \\
(\text { Mean } \pm \text { SD })\end{array}$ & $21.94 \pm 1.17$ & $21.74 \pm 1.37$ & 0.14 \\
\hline $\begin{array}{l}\text { Gender }^{b} \\
\text { - } \quad \text { Males n (\%) } \\
\text { - } \quad \text { Females n (\%) }\end{array}$ & $\begin{array}{l}43(26.7 \%) \\
118(73.3 \%)\end{array}$ & $\begin{array}{l}113(57.4 \%) \\
84(42.6 \%)\end{array}$ & $<0.001 *$ \\
\hline $\begin{array}{l}\text { Marital status } \\
\text { - } \quad \text { Single } \\
\text { - } \quad \text { Married } \\
\text { - } \quad \text { Divorced }\end{array}$ & $\begin{array}{c}156(96.9 \%) \\
3(1.9 \%) \\
2(1.2 \%)\end{array}$ & $\begin{array}{c}196(99.5 \%) \\
1(0.5 \%) \\
0(0 \%)\end{array}$ & 0.14 \\
\hline $\begin{array}{l}\text { Academic year }^{b} \\
\text { - Preclinical } \\
\text { - Clinical }\end{array}$ & $\begin{array}{c}56(34.8 \%) \\
105(65.2 \%)\end{array}$ & $\begin{array}{c}100(50.8 \%) \\
97(49.2 \%)\end{array}$ & $0.002 *$ \\
\hline $\begin{array}{l}\text { Grade in previous year }^{b} \\
\text { - Acceptable } \\
\text { - Good } \\
\text { - Very Good } \\
\text { - Excellent }\end{array}$ & $\begin{array}{c}1(0.6 \%) \\
47(29.2 \%) \\
51(31.7 \%) \\
62(38.5 \%)\end{array}$ & $\begin{array}{c}2(1 \%) \\
77(62.1 \%) \\
75(59.5 \%) \\
43(21.8 \%)\end{array}$ & $0.007 *$ \\
\hline
\end{tabular}

$a$ T-test was used.

${ }^{b}$ Pearson chi square test was used.

*statistically significant at $\mathrm{p}$ value $\leq 0.05$.

All 7 domains of stress exhibited significantly higher mean scores $(\mathrm{p}<0.001)$ among students in Alexandria university (72.74 \pm 12.64$)$ than pharos university $(62.48 \pm 14.46)$.Faculty and administration as well as workload domains showed the highest mean values of stress among both Alexandria students 
( $18.73 \pm 4.37$ and19.52 \pm 3.46 , respectively) and Pharos students ( $15 \pm 4.98$ and $16.83 \pm 4.31$, respectively) whereas performance pressure was the lowest in both faculties $(2.73 \pm$ 0.98 and $2.40 \pm 1.04$, respectively).Social stressors were nearly the same among both university students $(p=0.80)$ (Table 3).

Table (3): Comparison of stress levels between Alexandria and Pharos University students

\begin{tabular}{|l|c|c|c|}
\hline \multicolumn{1}{|c|}{ Domains } & $\begin{array}{c}\text { Alexandria } \\
\text { University (n=161) }\end{array}$ & $\begin{array}{c}\text { Pharos } \\
\text { University } \\
\mathbf{( n = 1 9 7 )}\end{array}$ & $\begin{array}{c}\text { P Value } \\
\text { T-test }\end{array}$ \\
\hline D1-Self-efficacy beliefs & $11.88 \pm 3.31$ & $10.95 \pm 3.44$ & $0.01^{*}$ \\
\hline $\begin{array}{l}\text { D2-Faculty and } \\
\text { administration }\end{array}$ & $18.73 \pm 4.37$ & $15.50 \pm 4.98$ & $<0.001^{*}$ \\
\hline D3-Workload & $19.52 \pm 3.46$ & $16.83 \pm 4.31$ & $<0.001^{*}$ \\
\hline D4-Patient treatment & $9.14 \pm 4.22$ & $6.90 \pm 3.56$ & $<0.001^{*}$ \\
\hline D5-Clinical training & $3.66 \pm 1.74$ & $2.89 \pm 1.48$ & $<0.001^{*}$ \\
\hline $\begin{array}{l}\text { D6-Performance } \\
\text { pressure }\end{array}$ & $2.73 \pm 0.98$ & $2.40 \pm 1.04$ & $0.002^{*}$ \\
\hline D7-Social stressors & $7.09 \pm 2.32$ & $7.02 \pm 2.66$ & 0.80 \\
\hline All Domains & $72.74 \pm 12.64$ & $62.48 \pm 14.46$ & $<0.001^{*}$ \\
\hline
\end{tabular}

Comfort in religion (88.3\%) as well as praying and meditation (88\%) were the most common coping strategies adopted by students, in both universities. Meanwhile, smoking tobacco and behavioral disengagement were the least used mechanisms (figure 1).



Figure 1: Different stress coping mechanisms used by students

The multivariable regression analysis, displayed in (table 4), shows that males were almost 5 times less stressed than females -4.91 $(-7.70,-2.13)$ and students of the public Alexandria University were 6.65 times more stressed than those enrolled in private Pharos University 6.65(3.90, 9.40). Moreover, students of preclinical years were 11.41 times less stressed than those in the clinical years $-11.41(-15.51,-7.30)$, with those having good grade in previous year being the least stressed among all participating students -3.01(-6.32, 0.19). Tobacco and drug use associated with lower stress than any other mechanism, whereas behavioral disengagement was the least effective $-2.05(-6.54,2.45)$.
Table (4): Multivariable regression analysis of the different factors and stress coping mechanisms affecting the total stress level among Alexandria and Pharos University students

\begin{tabular}{|c|c|c|c|c|}
\hline \multicolumn{2}{|c|}{ Variables } & B (95\% CI) & $\eta 2$ & P value \\
\hline \multicolumn{2}{|r|}{ Age } & $-0.03(-1.64,1.59)$ & $<0.001$ & 0.98 \\
\hline \multirow{2}{*}{ Gender } & Males & $-4.91(-7.70,-2.13)$ & 0.03 & $0.001^{*}$ \\
\hline & Females & \multicolumn{3}{|c|}{ Reference } \\
\hline \multirow[t]{2}{*}{ University } & $\begin{array}{c}\text { Public } \\
\text { (Alexandria) }\end{array}$ & $6.65(3.90,9.40)$ & 0.06 & $<0.001^{*}$ \\
\hline & Private (Pharos) & \multicolumn{3}{|c|}{ Reference } \\
\hline \multirow{2}{*}{$\begin{array}{c}\text { Academic } \\
\text { year }\end{array}$} & Preclinical & $-11.41(-15.51,-7.30)$ & 0.08 & $<0.001^{*}$ \\
\hline & Clinical & \multicolumn{3}{|c|}{ Reference } \\
\hline \multirow{4}{*}{$\begin{array}{c}\text { Grade in } \\
\text { previous } \\
\text { year }\end{array}$} & Acceptable & $-2.00(-17.50,13.49)$ & $<0.001$ & 0.80 \\
\hline & Good & $-3.01(-6.32,0.19)$ & 0.01 & 0.07 \\
\hline & Very Good & $-0.33(-3.58,2.92)$ & $<0.001$ & 0.84 \\
\hline & Excellent & \multicolumn{3}{|c|}{ Reference } \\
\hline \multicolumn{2}{|c|}{ Self-distraction } & $0.48(-3.12,4.07)$ & $<0.001$ & 0.80 \\
\hline \multicolumn{2}{|c|}{ Active coping } & $-1.52(-4.57,1.53)$ & 0.003 & 0.33 \\
\hline \multicolumn{2}{|c|}{ Tobacco or drug use } & $-2.05(-6.54,2.45)$ & 0.002 & 0.37 \\
\hline \multicolumn{2}{|c|}{$\begin{array}{l}\text { Emotional support from } \\
\text { others }\end{array}$} & $-1.72(-4.47,1.03)$ & 0.004 & 0.22 \\
\hline \multicolumn{2}{|c|}{ Behavioral disengagement } & $2.79(0.04,5.54)$ & 0.12 & $0.047^{*}$ \\
\hline \multicolumn{2}{|c|}{ Positive reframing } & $-1.80(-5.33,1.71)$ & 0.003 & 0.31 \\
\hline \multicolumn{2}{|c|}{ Planning } & $1.54(-1.97,5.04)$ & 0.002 & 0.39 \\
\hline \multicolumn{2}{|c|}{ Humor } & $0.53(-2.24,3.29)$ & $<0.001$ & 0.71 \\
\hline \multicolumn{2}{|c|}{$\begin{array}{l}\text { Comfort in religion or } \\
\text { spiritual beliefs }\end{array}$} & $-0.33(-4.50,3.85)$ & $<0.001$ & 0.88 \\
\hline \multicolumn{2}{|c|}{ Praying or meditation } & $1.81(-2.44,6.05)$ & 0.002 & 0.41 \\
\hline
\end{tabular}

\section{DISCUSSION}

Among all domains of stress exhibited significantly higher mean scores among students in Alexandria university were found than pharos university. Faculty and administration as well as workload domains showed the highest mean values of stress among both Alexandria students and Pharos students, whereas performance pressure was the lowest in both faculties.

Although the null hypothesis of the present research can be safely rejected due to the significant differences between Alexandria and Pharos University, nevertheless there are few limitations mainly attributed to the findings of the study can only be generalized to the specific study population selected, since the sample was a convenient sample. However in Alexandria these two faculties are the only available and established public and private dental faculties. Moreover, the lack of cut off values of the questionnaire mean scores which hindered the categorization of the stress levels among students. Another limitation is the expected reporting bias and relative subjectivity of the responses. This is attributed to the nature of the study design that mainly relied on questionnaire survey. However, the questionnaire was tested for internal consistency, therefore, was expected to provide sufficient valid responses from participants. Moreover, the clarity of questions, confidentiality of responses and anonymity of the questionnaire as well as the desire of students to share their opinions relating to this vital problem and hoping to find solutions all contributed to the high response rate.

Among the factors which might have contributed to the high response rate, of nearly $95 \%$, is the distribution of the questionnaire when almost all students were available for their practical or clinical sessions, as well as their high interest and willingness to complete the questionnaire. This may point to 
the awareness of the students regarding the importance of the study as a tool to disclose the sources of stress they were facing within their educational environment. It may also reflect their hopes, in the findings of the current study, to induce positive actions from the educational authorities and policy makers towards the alleviation of these stressors.

Moreover, preclinical students had significantly less amounts of stress, nearly 11 times, than clinical students. This may be attributed to the difficulties expected when dealing with patients, whether uncooperative or incompliant, in addition to the extensive tasks and assignments requested from final year students who worry about completing their clinical requirements or failing their courses as they approach graduation. Moreover, the students' future expectations of their career may be also an additional source of stress. The present findings again agree with those reported by Moustafa et al (8) as well as Grandy et al (10) and Pau et al(11).

The regression model also showed that behavioral disengagement was significantly $(p=0.047)$ the least effective coping mechanism since it was associated with higher levels of stress more than any other strategy whereas smoking and drug use, on the other hand, associated with lower stress, probably among male students. The current results may denote the increasing prevalence of smoking habit among the Egyptian youth who maybe consider it as a show off strategy rather than a stress relieving mechanism. Meanwhile, comfort in religion or spiritual beliefs and praying or meditating were the most common adopted coping strategies by students. Praying or performing spiritual activities was also reported among Malaysian dental students as a popular stress reduction technique(12), which is believed to provide calmness and bring about hope for better life situations.

A significantly higher mean score of stress was found, in all domains, among Alexandria University students. Meanwhile, work load domain was the highest which may point at the more demanding educational system of Alexandria University, inducing stress among students. These results are in agreement with Muirhead and Locker (13) who reported that falling behind with clinical requirements was among the highest six stressors among Canadian dental students. Similar results were also reported by various studies that considered lack of time for relaxation due to high workload as a major source of stress among dental students, such as those conduced among Saudi dental students (14).

Faculty and administration represented the second higher stressor, being also higher among Alexandria students and raising a question whether communication and interpersonal relationships are expected to be inadequate between students and staff in public universities. Nevertheless, due to the very large number of students in the laboratory and clinical sessions, instructors and staff may have some problems dealing with all students and their patients, together with their own research requirements and academic duties such as teaching, mentoring and patients' treatment, which may lead to inconsistency in their evaluations. The current results are again supported by Moustafa et al (8) who found that difference in opinion between clinical staff was reported to be the most stressful item among the majority of students, in Alexandria University. The present result is also in agreement with a study conducted on Turkish dental students during the academic year 2014-2015 (9).Inconsistency of feedback on the work performed by students, between different instructors, plays a major role as a source of stress for students. It puts them in a challenge facing different points of views of instructors and impairs their relation with faculty junior staff.

On the other hand, in both Alexandria and Pharos University, performance pressure was the least provoking factor. This may be because this domain contains only one question enquiring about grades which might not represent a source of stress for all students, equally. The current results were supported by Peker et al (15) who found that stress related to clinical competence decreased each passing year with the amount of clinical training and experience. However, this domain showed a significant difference with a higher stress level among Alexandria students. Again, the present findings emphasize the need for more attention to be given from the faculty administration, in Alexandria University, regarding the potential sources of stress in the educational environment via stress management programs to help students cope with the educational process, and thus develop a less stressful life style. The study findings recommend that the educational system is in need for re-evaluation with a shift towards a more student centered curriculum. Student-faculty interaction, meetings, detailed written comments/surveys and checklists can reflect the students' opinion and their provoking stressors at the educational system. Moreover the faculty administrators should implement effective stress relieving programs and increase the awareness of the students of how wisely they can use stress coping mechanisms.

\section{CONCLUSIONS}

Students of Public Alexandria University were found to have significantly higher mean scores of stress, in all seven domains. However, students, in both faculties, mainly suffered from the domains related to workload as well as faculty and administration. Praying and meditation were the most common stress relieving strategies used by all participants. The present findings; therefore, emphasize the pressing need to reduce such stressors during the academic dental education and to encourage constructive coping mechanisms.

\section{CONFLICT OF INTEREST}

The authors declare that they have no conflict of interest.

\section{REFERENCES}

1. Divaris K, Barlow PJ, Chendea SA, Cheong WS, Dounis A, Dragan IF, et al. The academic environment: the students' perspective. Eur J Dent Educ. 2008;12:120-30.

2. Elani H. Stress in dental students: A mixed methods study. Ph.D. Thesis.Department Public Health, Faculty of Dentistry, McGill University, Montreal. Canada:2012.

3. Gorter R, Freeman R, Hammen S, Murtomaa H, Blinkhorn A, Humphris G. Psychological stress and health in undergraduate dental students: fifth year outcomes compared with first year baseline results from five European dental schools. Eur J Dent Educ. 2008;12:61-8.

4. Humphris G, Blinkhorn A, Freeman R, Gorter R, HoadReddick G, Murtomaa 
et al. Psychological stress in undergraduate dental students: baseline results from seven European dental schools. Eur J Dent Educ. 2002;6:22-9.

5. Kay EJ, Lowe JC. A survey of stress levels, self-perceived health and health-related behaviors of UK dental practitioners in 2005. Br Dent J. 2008;204:E19.

6. Alzahem AM, Van der Molen HT, Alaujan AH, De Boer BJ. Stress management in dental students: a systematic review. Adv Med EducPract 2014;5:167-76.

7. El-Kashlan MK, Saleh SM. Perceived problems of dental students in relation to academic advancement in Alexandria University. ADJ. 1998;23:15-45.

8. Moustafa M, El-Kashlan M, Essam El-Din W. Perceived sources of stress among undergraduate dental students in Alexandria University. ADJ.2004;24:16-45.

9. Ersana N, Fisekcioglua E, Dolekoglua S, Oktayb I, Ilguya D.Perceived sources and levels of stress, general selfefficacy and coping strategies in clinical dental students. Psychol HealthMed. 2017;22:1175-85

10. Field A. Discovering statistics using IBM SPSS statistics. $4^{\text {th }}$ ed. London, Calofornia, New Delhi: SAGE publications Ltd; 2013.
11. Charan J,Biswas T. How to calculate sample size for different study designs in medical research. Indian J Psuchol Med 2013;35:121-6.

12. Grandy TG, Westerman GH, Lupo JV, Comb CG. Stresssymptoms among third-year dental students. J Dent Educ.1988;52:245-9.

13. Pau A, Rowland ML, Naidoo S, AbdulKadir R, Makrynika E, Moraru R, et al. Emotional intelligence and perceived stress in dental undergraduates: a multinational survey. J Dent Educ. 2007;71:197-204.

14. Ahmad MS, Yusoff MM, Abdul Razak I. Stress and its relief among undergraduate dental students in Malaysia. Southeast Asian J Trop Med Public Health. 2011;42:996-1004.

15. Muirhead V, Locker D. Canadian Dental Students' perceptions of stress. J Can Dent Assoc. 2007;73:323.

16. Al-Saleh SA, Al-Madi EM, Al-Angari NS, Al-Shehri HA, Shukri MM. Survey of perceived stress-inducing problems among dental students, Saudi Arabia. Saudi Dent J. 2010;22:83-8.

17. Peker I, Alkurt MT, Usta MG, Turkbay T. The evaluation of perceived sources of stress and stress levels among Turkish dental students. Int Dent J. 2009;59:103-11. 